\title{
RESENDE, VIVIANE DE MELO. ANÁLISE DE DISCURSO CRÍTICA E REALISMO CRÍTICO: IMPLICAÇÕES INTERDISCIPLINARES. CAMPINAS, SÃO PAULO: PONTES EDITORES, 93 PÁGINAS, 2009.
}

\author{
Resenhado por Elaine Caldeira ${ }^{1}$ \\ (Universidade de Brasília - UnB)
}

Viviane de Melo Resende é professora do Instituto de Letras da Universidade de Brasília (UnB), Doutora em Lingüística pela UnB/Universidade de Coimbra, é membro do Núcleo de Estudos de Linguagem e Sociedade (NELIS) do Centro de Estudos Avançados Multidisciplinares (CEAM) da Universidade de Brasília (UnB), do Grupo de Estudos de Linguagem do Centro-Oeste (GELCO), da Associação Latino-americana de Estudos do Discurso (ALED) e da Rede Latino Americana de Estudos de Discursos de Pessoas em Situação de Extrema Pobreza (REDLAD).

A sua mais recente obra publicada, Análise do Discurso Crítica e Realismo Crítico: implicações interdisciplinares, tem como objetivo central apontar a necessidade de maior reflexividade epistemológica em Análise do Discurso Crítica (ADC). É dividida em duas partes, sendo o foco da primeira a perspectiva ontológica que orienta pesquisas em ADC e o foco da segunda a filiação de pesquisa em ADC, a tradição da pesquisa qualitativa e a seleção por métodos etnográficos para a geração e coleta de dados. A autora defende que a epistemologia deve construir a ponte entre teoria e metodologia e que a coerência entre modelos ontológicos e epistemológicos adotados é fundamental para garantir a coerência também entre teoria e empiria. Para aprofundar essa visão, Resende parte do modelo de ADC desenvolvido por Normam Fairclough e da relação interdisciplinar que estabelece com o Realismo Crítico (RC). Visando aprofundar na reflexividade no desenho de

1. Doutoranda junto ao Programa de Pós-Graduação em Linguística da Universidade de Brasília. 
pesquisas, ela apresenta uma reflexão no primeiro capítulo sobre a constituição heterogênea de abordagens na ADC, argumentando que embora a ADC defina-se por uma heterogeneidade de abordagens, as propostas teóricas e metodológicas em ADC guardam algumas características em comum, o que confere coerência ao campo.

A autora destaca, dentre as abordagens críticas do discurso, três características fundamentais: a interdisciplinaridade, o caráter posicionado em face dos problemas sociais parcialmente discursivos e a utilização da Linguística como instrumento para a crítica social. Resende ressalta que os estudos discursivos têm atraído atenção de pesquisadores de diversas áreas devido às teorizações sociais baseadas na linguagem que estão na esteira de um processo concreto vivenciado nas práticas sociais contemporâneas, pois aponta que a vida social, de acordo Fairclough (2006), é cada vez mais mediada por textos e o papel dos textos na vida social é cada vez mais saliente em todos os campos da atividade humana, como por exemplo, na cultura, na política e na economia. Assim, baseando-se em Fairclough e Jessop Sayer (2002), a autora destaca o papel performativo da linguagem, embora aponte a lacuna existente entre teorizações baseadas na linguagem e pesquisas voltadas para uma exploração dos papéis da linguagem em práticas sociais contextualizadas deixadas, muitas vezes, por cientistas sociais e analistas de discursos.

Resende defende que a ADC procura superar essa lacuna contando com a consolidação de um corpo teórico da linguagem na sociedade que, alimentado nas Ciências Sociais, apresenta um foco mais específico nos modos como a linguagem figura na vida social e em um conjunto de métodos para a análise linguística de dados empíricos, entendendo o texto como unidade mínima de análise (WODAK, 2003). Dessa forma, para dar conta de sua relação com a teoria social crítica em termos teóricos da dimensão crítica assumida em termos práticos, a autora argumenta que a ADC busca o conceito de práticas sociais e de discurso, visto que a análise das práticas sociais constitui um foco "teoricamente coerente e metodologicamente efetivo" porque permite conectar a análise das estruturas sociais à análise da inter(ação) (FAIRCLOUGH, 2000). Nesse sentido, ela 
afirma que não há separação entre as perspectivas social e linguística nas análises, pelo contrário, uma análise discursiva crítica será tanto mais eficiente quando maior for a integração entre os pressupostos articulados na relação interdisciplinar.

Buscando estreitar as relações entre a ADC e as Ciências Sociais (CS), no segundo capítulo, Perspectiva ontológica da sociedade e discurso: $R C$ e $A D C$, Resende discute alguns preceitos básicos sobre a realidade social e sobre a relação entre estrutura social e ação social, focalizando as influências da ontologia do RC na ADC. Ela afirma que ontologia diz respeito ao modo como se entende a natureza do mundo social, aos componentes da realidade social, e que a adoção de uma perspectiva ontológica clara do mundo social deve ser o primeiro passo na definição de um planejamento de pesquisa (MANSON, 2002). Assim, destaca que a abordagem de ADC com a qual trabalha adota uma versão ontológica baseada no Realismo Crítico (FAIRCLOUGH, JESSOP \& SAYER, 2002).

Assim sendo, seleciona alguns aspectos relevantes do RC para embasamento de discussões em ADC. Dentre esses aspectos, Resende destaca a estratificação da vida social como sistema aberto e o modelo transformacional da relação entre estrutura e ação social. Com relação à estratificação da realidade social, a autora defende, de acordo Bhaskar (1989), uma ontologia estratificada do mundo social que sugere a existência de três estratos da realidade: o potencial (que refere-se às estruturas e poderes dos elementos sociais), o realizado (que refere-se ao que acontece quando esses poderes são ativados), o empírico (que refere-se àquilo que nós efetivamente observamos dos efeitos das estruturas, das potencialidades e das realizações). Desse modo, ela esclarece que para o RC a realidade é constituída não apenas de experiências e do curso de eventos realizados, mas também de estruturas, poderes, mecanismos e tendências de aspectos da realidade, que geram e facilitam eventos realizados que nós podemos (ou não) experimentar (BHASKAR E LAWSON, 1998). Apontando, assim, que a estratificação da realidade social significa que nem tudo o que poderia acontecer em função das estruturas internas dos objetos 
sociais acontece de fato, porquanto há contingências contextuais que podem bloquear mecanismos.

No terceiro capítulo, Representação e identificação, a autora aborda as duas funções da linguagem que se mostram centrais para o interesse específico de pesquisas etnográficas (discursivas, representação e identificação), baseando-se em alguns dos pressupostos da Linguística Sistêmica Funcional (LSF) e na recontextualização desses conceitos em ADC. Resende aponta que Fairclough (2003) propõe uma recontextualização da perspectiva multifuncional da linguagem em LSF. As três metafunções apresentadas por Halliday (2004) (interpessoal - ideacional - textual) são renomeadas por Fairclough (2003) para significados, o que não chega a ser uma novidade, segundo a autora, pois Halliday já falava em três linhas de significado. Entretatdo, ela destaca que a diferença entre as propostas de Halliday e Fairclough, no que se refere à multifuncionalidade linguística, é significativa em termos do conteúdo de alguns desses significados, já que a proposta de Fairclough (2003) ampliou o diálogo entre a LSF e a ADC ao propor os conceitos de gênero discursos e estilos como associados aos significados acional, representacional e identificacional, respectivamente.

No quarto e último capítulo da primeira parte do livro, Análise discursiva textualmente orientada, a autora procura enfatizar a relevância de análise discursivas textualmente orientadas para a crítica social, argumentando que para a ADC a relação entre linguagem e sociedade é interna, isto é, textos como parte de práticas sociais não apenas recebem informação oriunda das estruturas sociais como também tem efeito na reprodução/transformação dessas mesmas estruturas. Assim, em termos de escopo de aplicação, Resende, apoiando-se em Chouliaraki \& Fairclough, (1999), afirma que a ADC acrescentou aos estudos linguísticos um interesse na investigação dos aspectos discursivos de práticas problemáticas na vida social contemporânea.

$\mathrm{Na}$ segunda parte da obra, A construção do conhecimento em ADC: reflexão epistemológica e os estudos críticos do discurso, Resende dá continuidade as reflexões apresentados na primeira parte 
procurando justificar a filiação de pesquisas em ADC a tradição da pesquisa qualitativa e a seleção por métodos etnográficos para a geração e a coleta de dados. No quinto capítulo, a partir da ênfase na relevância das reflexões de cunho epistemológico, a autora procura contribuir para a superação da lacuna epistemológica que considera um problema em ADC. Ela defende que o modelo epistemológico abordado em uma pesquisa precisa ajudar a produzir conhecimento acerca dos componentes ontológicos do mundo social, de acordo com a versão da ontologia considerada para a pesquisa.

Ao considerar que existe uma incongruência entre a pesquisa ontológica de ADC e sua tradição de análise documental isolada, visto que se os componentes do mundo social são práticas sociais compostas de relações sociais, ideologias, atividades materiais e discursos, e se esses elementos da prática social são dialeticamente interconectados e não se podem reduzir um ao outro, Resende afirma existir uma incongruência entre essa ontologia e a postura epistemológica que acredita que essa realidade social pode ser conhecida simplesmente por meio do discurso materializado em textos. Assim, a autora defende que a epistemologia que dá conta de práticas e redes de práticas tem de ser mais reflexiva de sua prática e precisa articular outros métodos além da coleta de documentos, pois análises discursivas críticas baseadas apenas nesses métodos, não conseguem realizar epistemologicamente o potencial da perspectiva ontológica adotada pela ADC - baseada em uma realidade social estratificada composta de práticas e redes de práticas. Nesse sentido, ela acredita que é possível potencializar a relação entre a ADC e a Ciência Social Crítica (CSC) formulando questões que ajudam a perceber a dialética entre representação e identificação e sugerindo caminhos para superar a indesejável divisão entre estrutura e ação.

No sexto capítulo, Pesquisa qualitativa, a autora explicita a filiação do seu trabalho à tradição da pesquisa qualitativa (PQ), já que considera que essa é uma forma de pesquisa potencialmente crítica que permite as Ciências Sociais Críticas identificar estruturas de poder naturalizadas em um contexto sócio-histórico definidos. Dessa forma, considera que a pesquisa qualitativa é indicada quando se pretende 
focar representações do mundo, relações sociais, identidades, opiniões, atitudes e crenças ligadas a um meio social. Já nos capítulos sétimo e oitavo, Realismo Crítico e Epistemologia nos Estudos Críticos do Discurso e Realismo Crítico e Análise de Discurso Crítica, a autora destaca implicações epistemológicas do Realismo Crítico para a Análise de Discurso Crítica. No sétimo capítulo, Resende aborda algumas implicações epistemológicas da ontologia do Realismo Crítico. Dentre essas, estão a estratificação da realidade social nos domínios do potencial, do realizado e do empírico; a discussão realista crítica das dimensões intransitiva e transitiva; o aspecto epistemológico do modelo transformacional da relação entre estrutura e ação social.

Em relação à estratificação da realidade social nos domínios do potencial, do realizado e do empírico, Resende observa que a redução da realidade ao estrato empírico tem por base a estratificação de realidade social no RC, segundo a qual se distinguem os domínios do potencial, do realizado e do empírico. Ela destaca que enquanto o potencial e o realizado são categorias ontológicas, referentes respectivamente às estruturas e aos poderes causais dos objetos sociais e ao que se realiza quando esses poderes causais são ativados em eventos, o empírico é uma categoria epistemológica que se refere ao que podemos observar (FAIRCLOUGH, JESSOP \& SAYER, 2002). Em relação à perspectiva transformacional da relação entre estrutura e ação social, a autora considera que essa perspectiva é fundamental para uma ciência crítica que procura estudar questões problemáticas na vida social, como por exemplo, a exclusão social. Nesse sentido, Resende defende que o foco nas relações sociais como estruturadas, isto é, pré-existentes, garante uma perspectiva transformacional entre tais relações e as atividades em que atores sociais se engajam, visto que as relações préestabelecidas são condições necessárias para os eventos estruturados por essas relações, e os eventos são potencialmente transformadores dessas mesmas relações dependendo das contingências textuais.

No último capítulo, Realismo Crítico e Análise de Discurso Crítica, ressalta a autora que, embora os problemas dos analistas de discurso sejam de caráter social, e por isso mesmo dialogam com as teorias sociais, é importante que analistas de discurso mantenham 
sua identidade, uma vez que o foco de analistas de discurso não são primariamente as atividades materiais ou as estruturas sociais de um modo amplo, mas o momento discursivo das práticas, as relações de emergência entre aspectos discursivos e não discursivos na reprodução/transformação da sociedade. Assim, ela chama atenção para a necessidade de se fazer reflexões que permitam adaptar categorias e conceitos, oriundos das Ciências Sociais, aos interesses e necessidades da ADC.

O trabalho de Resende nesta obra enfatiza e explica, portanto, a relação entre sociedade e discurso, propondo uma perspectiva ontológica para a Análise de Discurso Crítica (ADC) ao centrar-se na relação entre prática social e discurso. Nesse sentido, este trabalho é de grande importância para analistas que pretendem realizar análises discursivas textualmente orientadas, pois esclarece conceitos complexos derivados do Realismo Crítico e da Linguística SistêmicoFuncional que são apropriados pela ADC, visando com isso, fornecer subsídios para superar a lacuna existente entre teorizações baseadas na linguagem e pesquisas voltadas para uma exploração dos papéis da linguagem em práticas sociais contextualizadas. 